\title{
Pesquisa São Paulo: Sociologia, cinema e memória
}

\section{Fernando José Filho ${ }^{1}$}

"É uma visão que os nossos olhos já construiram: São Paulo, metrópole formidável e cyclopica, colocando-se, em alguns decênios, na vanguarda dos maiores centros de atividade do mundo" (São Paulo, sinfonia da metrópole)

"Pois eu conheço este café há vinte anos. Como passa o tempo, heim? Isto aqui era calmo, sossegado, cheio de mesinhas. Não tinha esses afobados que derrubam o café na gente" (Simão, o caolho) "O amor é pessoal e intransferível" (São Paulo S/A)

\section{Resumo}

$\mathrm{O}$ texto a ser apresentado consiste em um pequeno recorte do desenvolvimento e resultados da pesquisa São Paulo: Sociologia, cinema e memória. Em seu terceiro ano de financiamento (PIBIC) da UNIFESP na modalidade Ações Afirmativas, 2010-2012, esta pesquisa conseguiu atingir alguns objetivos em relação àquilo que ela pretendia evidenciar dentro do campo das ciências humanas, especialmente os estudos sobre ciências sociais e cinema. A pesquisa analisou três filmes que tiveram a cidade São Paulo como "cenário" privilegiado das filmagens: o documentário São Paulo, sinfonia da Metrópole (São Paulo, sinfonia da Metrópole, Adalberto Kemeny e Rodolfo Rex Lusting, 1929) e as ficções Simão, o caolho (Simão, o caolho, Alberto Cavalcante, 1955) e São Paulo S.A (São Paulo S.A, Luiz Sérgio Person, 1965). A partir da análise de cenas destas obras procurou se discutir a relação memória, cidade e cinema.

\footnotetext{
${ }^{1}$ Iniciação Científica e Monografia. Ciências Sociais - $8^{\circ}$ termo. Universidade Federal de São Paulo, orientador: Mauro Rovai.

E-mail: jose.fernando@ig.com.br
} 
Palavras-chave: cinema, memória, cidades, São Paulo

\section{Os Filmes}

"São Paulo, a symphonia da metrópole (1929) é o mais importante documentário urbano da era silenciosa no Brasil”. Dirigido pelos húngaros Adalberto Kemeny e Rodolfo Rex Lustig, trata-se, na visão de Rubens Machado Júnior (1989, p.21), do documentário de longa-metragem que "configura a um só tempo o exemplo máximo de acabamento técnico e qualidade estética de toda esta produção do período". A obra, sobre alguns aspectos, pode ser pensada no âmbito das "sinfonias urbanas" realizadas nos anos de 1920, como os filmes Rien que lês heures (Rien que lês heures, Alberto Cavalcanti, 1926), O homem com a câmera (Chelovek s kinoapparatom., DzigaVertov, 1929) e Berlim, a sinfonia da metrópole (Berlin: Die Sinfonie der Grosstadt., Walter Ruttmann, 1927). Os diretores percorrem a cidade filmando imagens do dia a dia, que possam enaltecer a metrópole: carros, máquinas industriais, pessoas correndo apressadamente, pessoas trabalhando. Através dos letreiros dos filmes, o expectador é informado sobre as funções de cada uma das instituições, e como elas devem desempenhar para que a cidade se torna uma grande metrópole, como por exemplo sobre a descrição da Penitenciária do Estado: "aqui, o trabalho, a disciplina e a bondade resgatam a falta cometida o conduzem o homem à comunhão social". Esse documentário nos apresenta como panoramas discursivos, as transformações das grandes cidades e estruturas as quais podemos diferenciar uma metrópole de uma vila provinciana.

Simão, o Caolho é o primeiro filme dirigido por Alberto Cavalcanti no Brasil. Estrelado por Olympio Bastos (mais conhecido como Mesquitinha), é uma obra inspirada nas crônicas de Galeão Coutinho, estreando em 
novembro de 1952, na inauguração da I Mostra Retrospectiva do Cinema Brasileiro em São Paulo. Nas palavras de Maria Rita Galvão, o diretor foi "calorosamente recebido, aplaudido durante muito tempo pela imensa platéia a abarrotar o cinema Paramount" (cf. Maria Rita Galvão apud Catani, 1983, p. 246). Simão é um homem malandro, simples e brincalhão, na qual a única coisa que quer ter mais na vida é um olho. E com este sonho, chega a sonhar a ser presidente da República, com um caráter autoritário e populista. O filme satiriza o então na época presidente Getúlio Vargas e nas palavras do crítico Almeida Salles "eleva a comédia de costumes e a sátira social a um nivel ainda não alcançado pelo nosso cinema”, retratando com admirável sutileza, vários aspectos da vida da classe média paulista, recriando a atmosfera doméstica e de rua, do centro e dos bairros da Capital, num intervalo de 20 anos (CATANI, p. 145).

O último filme analisado é São Paulo, S/A do diretor Luiz Sérgio Person, e protagonizado por Walmor Chagas e Eva Wilma. São Paulo S/A é ambientada no período da instalação das grandes multinacionais do ramo automobilístico no estado de São Paulo. Com isso, várias pequenas empresas vinculadas a este setor também surgiam para dar um suporte e ficam dependentes destas multinacionais: oficinas, concessionárias, lojas especializadas, e Carlos é o gerente de umas destas lojas. "Person não quis fazer um filme sobre grande empresários do setor automobilístico e sim de pessoas comuns que aproveitaram esse momento para montar pequenas fábricas, situadas nas dependências da grande indústria" (texto do catálogo do filme). $\mathrm{O}$ filme mostra a maneira que Carlos lida com as transformações urbanas e industriais que a cidade se coloca.

O próximo passo é compreender os elementos comuns de uma obra fílmica (composição dramática das personagens, imagens, montagem de 
cenas, movimentos de câmera e os fenômenos sonoros) em relação ao seu desenvolvimento na história do cinema, e também como eles se destacam e se diferenciam de filme para filme na pesquisa. Esses elementos fazem parte da estética do cinema na qual Jacques Aumont aponta que "a estética do cinema é, portanto, o estudo do cinema como arte, o estudo dos filmes como mensagens artísticas" (p. 15, 2011). Portanto são através de mensagens artísticas que são representados os elementos sociológicos da cidade de São Paulo.

A pesquisa também se pretendia pesquisar a representação da cidade paulistana no cinema, portanto, foi- se necessário aprofundar sobre a sociologia das cidades e história da cidade na primeira metade do século XX - como foi o seu processo de desenvolvimento econômico, populacional e cultural, e principalmente, como foi esse impacto na vida do indivíduo, que via pelas janelas, a sua cidade deixando de ser uma vila provinciana para uma metrópole com grandes avenidas, arranha-céus, fábricas e pessoas que começam a correr pelas ruas para chegar ao seu destino - todas essas mudanças ocorrendo em curto espaço de anos. O texto As grandes cidades e a vida no espírito (1903), de Georg Simmel busca entender exatamente as transformações psíquicas do individuo em frente "a vida nervosa" de uma cidade grande. Para ele, o indivíduo da metrópole reage aos estímulos nervosos da cidade com entendimento e uma racionalidade, diferente do homem campesino que se pauta por relações de sentimento. Isso também para o autor se dá pelo fato que as grandes cidades têm suas relações construídas pelo ritmo econômico (ou seja, pelo capital). Em São Paulo, sinfonia da metrópole e São Paulo S/A, a cidade é mostrada neste ponto. No documentário são enfatizados os aspectos econômicos, industriais e intelectuais como elementos positivados e desejantes de um indivíduo 
metropolitano e necessários para uma cidade que reivindica um status de metrópole. Em São Paulo S/A, Carlos é um personagem estritamente racional em suas atitudes, sempre tratando suas amantes com frieza, e na medida em que a ficção vai mostrando a cidade sendo "dominados" pela indústria automobilística, os seus personagens, nas palavras do diretor Person se tornam dentes de uma engrenagem. Estes personagens, para o sociólogo Waldir Salvadore "são membros de uma sociedade anônima paulistana" (Salvadore, 2005), ou seja, são co-responsáveis na construção de uma nova ordem subjetiva nas grandes cidades. Na medida em que a cidade de São Paulo cresce, se ramifica e fragmenta-se, "o caos interior do personagem principal (Carlos) também se fragmenta, o núcleo dramático se esgarça, o próprio filme é narrativamente descontínuo" (Salvadore, 2005). Portanto, Person mostra uma São Paulo num ponto mais negativo e cruel (ou engendrador) na vida psíquica dos seus habitantes, porém revelando esse como resultado de escolhas pautadas pela economia monetária. A São Paulo de Simão, o caolho é mostrado nos seus aspectos cotidianos. O filme é dividido temporalmente em duas fases - a primeira, São Paulo é mostrado mais parecido com uma vila. Simão freqüenta bares onde pode conversar e contar piadas e colocar tudo no "fiado". Sua esposa Marcolina se veste com roupas elegantes e usando jóias e adornos diversos, e recebe visitas ilustres para confraternizar em um chá da tarde na sua casa grande e mobiliada com empregada doméstica. Na segunda fase (numa passagem de 20 anos), o casal mora numa casa num bairro de nordestinos e imigrantes, numa situação inferior a que eles moravam na primeira fase do filme, mostrando assim, uma cidade com seus primeiros bairros divididos nitidamente em classes sociais. A sua casa não contém os móveis elegantes, mas móveis com aspectos de usados ou quebrados, as visitas agora são de moradores da vila que entram 
pela porta correndo para pegar algo emprestado ou fazer fofocas, a família não tem mais empregada domestica, deixando a cargo de Marcolina a realização destas tarefas. O personagem Simão estranha o bar. As pessoas que o frequentam entram e saem correndo após o pedido atendido. O recinto não tem mais mesas e sim balcão. A atendente não tem tempo para "prozear" e aceitar os galanteios de Simão. Simão estranha à cidade de São Paulo com arranha-céus, luzes e pessoas mal-educadas.

\section{A Memória}

A socióloga Myrian Sepúlveda dos Santos através do livro A memória coletiva e Teoria Social conceituam duas correntes de estudos sociais sobre a memória. A primeira inspirado por Maurice Halbwachs de que a continuidade dos laços de solidariedade através do tempo é celebrada por meios de rituais, comemorações, monumentos, museus e instituições diversas, mantido e transmitido por grupos sociais (familiares, religiosos e trabalhadores) através da memória coletiva. A segunda forma faz críticas pesadas as concepções de temporalidades e objetivações das memórias coletivas. Autores como Walter Benjamin, Sigmund Freud, Herbert Marcuse e Jacques Derridá não aceitam "a soberania do presente na construção do passado, pois deste último constatam sua permanência e seu poder disruptivo, ainda que sob diferentes formas: arquivos, imagens, ruínas, fragmentos, pesadelos, traumas, utopias e heterotropias" (SANTOS, 2012, p. 10).

O conceito de memória aparecia nestas obras entrelaçado com os temas de cidades e cinema. A pesquisa sobre memória nestes filmes passava por dois critérios. No primeiro na qual o próprio filme se torna um documento de um período histórico, e, portanto, capaz de guardar uma 
memória de uma época. São Paulo, sinfonia da metrópole é um exemplo de documento, pois ele não serviu apenas para entreter o público e sim um objeto de vitrine para sociedade paulistana das potencialidades que a cidade poderia apreender para ela. Eduardo Morettin (2005) coloca que as sociedades se esforçam em construir uma memória de si, através da mobilização de imagens e fincadas na afirmação de um domínio tecnológico. As imagens captam o real e permitem registrar a memória de eventos, personagens e ações que transformam a obra fílmica em um monumento e um objeto da própria história:

"o cinema espelha a vontade de justificar as ações do presente à luz das projeções iluminadoras do passado e de garantir para as gerações futuras, por meio de constantes exibições em diferentes espaços e para muitos expectadores, a efetividade da construção simbólica que faz do tema da permanência de sua imagem (...) o documento é monumento. Resulta do esforço das sociedades históricas para impor ao futurovoluntária ou involuntariamente-determinadas imagens de si próprias". (Eduardo V. Morettin, 2005, p.141).

Em Simão o Caolho, os personagens não estão num processo de memória de algum fato do passado ou relembrando algum processo, porém assim como São Paulo, a symphonia da metrópole, o filme de Cavalcante também se torna um documento de uma época. Simão, por exemplo, em determinada momento da obra sonha sendo presidente da república com característica de um mandante populista e autoritário - a de se supor, que o filme satiriza o presidente Getúlio Vargas, por a história se passar no período do seu governo - décadas de 40 e 50 . Porém em alguns momentos se aproxima da segunda concepção na quais sonhos e utopias do personagem Simão se tornam fundamentais na sua construção subjetiva 
A memória também está presente em Carlos. Após a briga com sua esposa Luciana, caminhando pelas ruas do centro da cidade, ele retorna cinco anos, no momento e relembra a trajetória, do ponto em que começa a fazer parte do processo de desenvolvimento da cidade até desembocar na briga e rompimento do seu casamento, e numa fuga em direção para fora dos limites da cidade. Para Salvadore (2005), "Carlos vive um mal-estar, lembrando o de Oscar Wilde, não ousa dizer nome" (p. 139). Carlos foge da cidade, mas retorna. Hilda, sua amante também sofre de um mal-estar, e sua opção é o suicídio - ela não consegue transferir ou transpor seu amor nesta cidade, ou seja, vítimas do "complexo econômico-social da urbe como quer Almeida Salles (1988:298), mas também algoz de si e terceiros" (Salvadore, 2005, p. 141).

\section{Referências}

ANDREW, Dudley J. As principais teorias do cinema. Uma introdução. Trad. Teresa Ottoni. Rio de Janeiro: Zahar, 1989.

AUMONT, Jacques. A imagem. Campinas: Papirus Editora, 1993. $16^{a}$ edição.

BENJAMIN, Walter. (1980) A obra de arte na época de suas técnicas de reprodução.In: Os Pensadores. São Paulo: Abril Cultural, p. 3 - 28.

CARONE, Edgard. A evolução industrial de São Paulo (1889-1930). São Paulo: Editora Senac, 2001.

CATANI, Afrânio M. "Segunda fase: o buraco n'água". In A Sombra da outra (um estudo sobre a cinematografia Maristela e o cinema industrial paulista dos anos 50). Dissertação de Mestrado. FFLCH-USP: São Paulo, 1983. p. 599.

CHARNEY, Léo;SCHWARTZ, Vanessa (org).O cinema e a invenção da vida moderna. São Paulo: Cosac Naif, 2001.

GALVÃO, Maria Rita Elieser. Crônica do Cinema Paulistano. São Paulo: Ática, 1975.

GIDDENS, Anthony.A transformação da intimidade: sexualidade, amor e erotismo nas sociedades modernas. Trad: Magda Lopes. São Paulo: Editora Unesp, 1992.

HALBWACHS, Maurice. A memória coletiva.Trad: Beatriz Sidou. São Paulo: Editora Centauro, 2004 
KRACAUER, Siegfried.O ornamento da massa. Trad: Carlos Eduardo J. Machado, Marlene Holzhausen. São Paulo: Cosac Naif, 2009.

LABAKI, Amir. Introdução ao documentário brasileiro. São Paulo: Francis, 2006.

MACHADO JR., Rubens L. R. São Paulo em movimento. A representação cinematográfica da metrópole nos anos 20. Dissertação de mestrado. ECA-USP, 1989, 160p.

MORAIS DA COSTA, Fernando. O som no cinema brasileiro. Rio de Janeiro: 7 Letras, 2008.

MORETTIN, Eduardo Victório. Dimensões históricas do documento brasileiro no período silencioso. Revista Brasileira de História. São Paulo, v.45, nº49 p.125-152-2005.

NAZARIO, Luiz (org). A cidade imaginária. São Paulo: Perspectiva, 2005.

PAIVA, Samuel; SCHVARZMAR, Sheila (org). Viagem ao cinema silencioso no Brasil. Rio de Janeiro: Editorial Beco do Azougue, 2011.

RAGO, Margareth. A invenção do cotidiano na metrópole: sociabilidade e lazer em São Paulo, 1900-1950. PORTA, PAULA (org). Historia da Cidade de São Paulo: a cidade a primeira metade do Século XX. São Paulo: Paz e Terra, 2004. P. 387-453

ROVAI, Mauro Luiz. (2005) Imagem, tempo e movimento. Os Afetos "Alegres" no filme $O$ Triunfo da Vontade, de Leni Riefenstahl.São Paulo: Humanitas/FAPESP.

SIMMEL, Georg. (1998) O dinheiro na cultura moderna. In: Jessé Souza e B. Oëlz (orgs), Simmel e a Modernidade. Brasília: Editora UNB, pp. 109 a 117.

SIMMEL, Georg. (1983). O estrangeiro. In: Evaristo de Moraes Filho (org.), Simmel Sociologia. São Paulo: Ática. Coleção Grandes Cientistas Sociais, vol. 34. p.182-188.

WEBER, Max. (1986). A 'objetividade' do conhecimento nas Ciências Sociais. In: Coleção Grandes Cientistas Sociais: Max Weber. São Paulo: Ática, v.13, pp. 79 - 127 e 128 - 41.

\section{Filmografia}

Berlim, sinfonia de uma metrópole - 1927. Dir. Walter Ruttmann. Alemanha. P\&B, 65 min. Título original: Berlin: Die Sinfonie der Grosstadt.

O homem com a câmera -1929. Dir. DzigaVertov. (ex)União Soviética. P\&B, 68 min. Título original: Chelovek s kino-apparatom.

Rien que les heures - 1926. Dir. Alberto Cavalcanti. França. P\&B, 45 min.

São Paulo, a symphonia da metrópole. Dir. Adalberto Kemeny e Rodolfo RexLustig. Brasil, $\mathrm{P} \& \mathrm{~B}, 90$ min.

São Paulo S/A - 1965. Dir. Luis Sérgio Person. Brasil, P\&B, 111 min.

Simão, o Caolho - 1952. Dir. Alberto Cavalvanti. Brasil, P\&B, 93 min. 